\title{
Emerging Market Economies in Conflict: Growth Economics and an Econometric Model for Political Instability
}

\author{
Shashank Sreedharan ${ }^{1}$, Shreyes Shyamsunder ${ }^{2}$ \\ ${ }^{1}$ School of Liberal Studies, Pandit Deendayal Petroleum University
}

\begin{abstract}
The International Political Economic landscape in the 21st century is, among others, impacted substantially by two broad phenomena - conflict and growth. There have been several general studies correlating these two variables. However, the crux of the debate lies in understanding how to sustain growth despite conflict. This paper attempts to understand the growth economics of emerging market economies that are prone to conflict. Multiple measures of international and internal conflict are considered to understand the spectrum of influence of conflicts on the range of macroeconomic variables. For instance, fighting a war on the borders leads to a large scale utilization of capital that could have been used elsewhere for a development oriented agenda. However, wars have shown a marked increase in productivity of both labour and capital (MPk and MPL). Furthermore, large scale ethnic conflicts for instance, have proved to be hugely detrimental to economic growth. Low intensity conflicts, on the other hand, have sometimes led to an upward trend in the macroeconomic indicators of economic growth. In recognizing a research gap in the form of a pressing need to construct a model with a practical application for organizations working towards Conflict Remediation and research in fields such as Peace Studies, this paper shall attempt to propose a new Political Instability Index as a part of an econometric model regressing parameters such as economic growth and the Global Peace Index (GPI). Along with a larger macroeconomic examination of the growth economics of two counties - Nigeria and Turkey members of the N-11 and MINT groups of states, this paper (and model) aspires to contribute to the goal of maintaining peace and sustaining high growth levels by helping relevant organizations monitor economic growth indicators to indicate a change in political stability and vice versa. Through such measures, it may be possible to predict changes in growth rate or forecast turmoil, which may then be mitigated. Therefore, through this research, we hope to enhance an understanding of the growth economics of emerging market economics which are prone to conflicts.
\end{abstract}

Keywords: Growth Economics, Conflict, Econometric Model, Macroeconomic indicators, MINT

\section{Introduction}

The Realist Theory of International Political Economy implies the inevitability and continuity of conflict alongside growth. While there is substantial work exploring the relationship between the two (through several proxy variables, each with compelling pros and cons), the increased frequency or persistence of conflict in the 21st century makes it important to understand the relationship between economic performance and political instability in a more functional manner, rather than solely theoretical from a policy perspective. The relationship is extremely peculiar and is influenced by a large number of factors which often differs from case to case in terms of specifics. To that end, we put forth a working classification for extent of development of countries for this paper to substantiate the conclusions: developed countries (largely, the OECD states), developing countries and lower development countries. The foremost stratum has been largely stagnant since the turn of the century, capably dealing with its peculiar development problems, although exceptions exist (for instance, Greece). It is the countries in the middle bracket that is of particular significance because their development trajectory answers important questions regarding growth and asks new ones. Emerging Market Economies such as Turkey, Nigeria have been growing at an impressive rate. They may soon challenge the current economic power configuration of the world, as well as help establish a path for poorer states to follow.

According to Polachek, Sevastianova (2010), empirical results revealed that interstate conflict has a negative influence on economic growth within a range of 0.18 to 2.77 percentage points while intrastate conflict causes a negative turn within the range of 0.01 to 0.13 percentage points. The interesting conclusions of this paper, however, were the variety of ways in which political instability affected economic performance. Firstly, the impact is predominantly short run, since countries begin to recover in the long run. Secondly, poorer economies such as the one in the third bracket of the above classification were prone to intrastate conflict while first bracket 
economies were the ones who were party to international wars. Specifically with respect to OPEC economies, conflicts positively affected economic performance. The motive behind the current research lies in this conclusion and an important question: under what circumstances would a state and/or another actor choose conflict to augment economic performance? How can we devise an easy, minimalist model to help relevant parties (such as organizations working in conflict zones in remediation operations) monitor the trends and take action in preparation as well as mitigation? An underlying assumption behind all conclusions of this paper is the accuracy of the conclusions drawn by Polachek, Sevastianova (2010), whose empirical evidence is based on sound data such as the Correlates of War (COW), Penn World Tables, and World Development Indicators etc.

\section{Emerging Market Economies: The Conflict-Growth Duality}

\subsection{Conflict: A driver of economic growth?}

When a country is embroiled in conflict on its borders and/or with external actors, there is a large utilization of capital. This capital may have been put to use for a host of developmental efforts. However, fighting a large scale conflict brings with it a considerable increase in productivity of both labour and capital (MPL and MPk). In other words, fighting a war causes money to be pumped in into the economy, which is considered growth in the conventional sense of growth. Let us consider the example of an emerging market economy - Nigeria - to illustrate the flaw in this framework. For over three decades, Nigeria has been growing steadily barring the economic slump in the 80s. It has been the fastest growing economy in Africa and has been touted to have the largest average growth rate within the next two or three decades. Nigeria still ranks poorly on the HDI and is a victim of the 'Trickle Down Paradox' - enormous revenues generated by a thriving oil sector does not reach the populace. Low intensity conflicts have sometimes led to an augmentation in the indicators of economic growth. We plotted economic growth against area of conflict from 1990-2010 for another emerging market economy Turkey - to find an interesting pattern. Despite the absence of a consistent trend, it was observed on multiple years that economic growth increased with an increase in the size of conflict area (Appendix 1).

One of the earliest and prominent empirical studies on the conflict-growth relationship was conducted by Barro (1991). Using number of coups per year and number of political assassinations per million people per year as proxy variables, instability was shown to have a negative relationship with growth. In the year 1993, Barro \& Lee as well as Easterly \& Rebelo found insignificant values while regressing a relationship between political instability measured by war as a dummy variable by the former and coups, war casualties etc. by the latter. In stark contrast, a distinct negative relationship was found by Jong-A-Pin in 2009. Most econometric models examining the conflict-growth relationship use civil wars to study the impact on the economy. In theory, conflict creates uncertainty which in turn leads to reduction of FDI and creates an atmosphere of distrust, detrimental to trade. There is deep depreciation of physical as well as human capital and disruption in market activity. However, most such models do not quite study the impact of international or inter-state wars. A more pressing concern in today's political landscape is the need to account for sub-conventional warfare or terrorism, as states devote substantial resources to fight non state actors such as terrorist outfits within and outside their borders, as well as other insurgents. This is further substantiated by the steady increase in defence expenditure in the annual budgets of most states in the first two brackets according to the development classification given above.

This paper, after carefully studying the design and output of the models mentioned herewith as well as under references, attempts to point out the major shortcomings and deficiencies in existing studies. Firstly, these studies fail to account for intensity/severity of war and the time extent of the spill over effect. Effects of civil wars on the economy are in the short run, but studies are conducted over 20-30 year time periods. Similarly, an interstate war or a war of secession such as the India-Pakistan partition of 1947 may have after effects decades after the conflict due to resource allocation and other factors. Secondly, while studying the conflict-growth relationship; existing studies attempt to examine the effects of various parameters but not the interaction between the parameters. In econometric terms, there is considerable scope for autocorrelation, whose effect is important to ensure efficacy of the regression model. Interaction between parameters may be within the same parameter across time. Countries with a history of political upheaval may be more prone to insurgency under a new regime, which is not factored in. Thirdly, these studies treat economic growth as synonymous with development, which is cause for concern. Growth without development is a major worry for emerging market economies and poorer states. Fourthly, these models absolutely fail to account for the institutional and structural variables that have a huge impact on the conflict-growth relationship. In Nigeria, for instance, the oil revenue 
influx is massive. However, one of - if not the undisputed - the main reasons for Nigeria's poor development track is the autocracy and deep rooted corruption of the Nigerian National Petroleum Corporation (NNPC). The solutions to Nigeria's economic inequality and distributional problems are rooted in weeding out corruption and institutional reforms rather than monetary and/or fiscal policy. The implications of this deficiency are larger these models, while purely theoretical rather than functional, are unable to factor in cause-effect relationships or measure impact with respect to democracy vs. dictatorial regimes, countries in Africa which are rife with internal conflict and a colonial history of exploitation vs. countries in the Middle East rife with ethnic fracturing as well as border and sub-conventional conflicts.

We would like to add further relevance to this paper by asking an extremely important question that other researchers and us must strive to answer in future efforts - do states invite or instigate conflict to boost their economy? Can conflict be stirred by design in a way that it increases productivity without a negative opportunity cost - can conflict have a positive utility function attached to it from the state's perspective?

\subsection{The Political Instability Index}

The functional model called for in the next section makes use of the Political Instability Index given in the Economist with 2009-10 values. Needless to say, the application of the model to real world situations will be with updated values, which may be calculated for any country with assistance from government data for the current year or year required.

The purpose of a functional model is derived from the failure of existing models to predict outbreaks of political turmoil and resulting economic slumps. This index factors in inequality, prior history of instability, ethnic fragmentation, poor governance, frequency of labour unrest (a measure of human capital depreciation), and magnitude of provision of state services. In studying existing models, decline in economic performance has emerged as a necessary but insufficient condition for new political instability. When accompanied by institutional or structural vulnerability (Realist Theory of IPE), economic distress has seen to lead to high levels of political unrest.

The index itself has a range of 0-10. It constitutes 15 indicators, 12 of which represent underlying vulnerability factors and the remaining account for economic distress. Inequality is measured by the classical parameter of Gini coefficient, State History is measured by an ordinal measure of number of years since independence, Corruption is measured by EIU rankings, Ethnic Fragmentation by the Ethnic Fractionalization Index (Alesina 2003), Trust in State Institutions by Barometers Polls of the World Values Survey, Status of Minorities by the Minorities at Risk Project (MRP) values, history of political instability, and frequency of labour unrest (EIU). Equally importantly, the regime type and neighbourhood situation are also factored in mathematically in a standardized scale allotment. In order to measure development in a more rounded manner versus merely economic growth, these factors are measured alongside the per capita GDP at PPP, the rise in income levels and unemployment levels in terms of \% of population.

Using this index for Political Instability in a model to simultaneously determine growth and conflict measure is a marked improvement on previous models from a functional perspective for actors who need to constantly monitor these parameters to take preparatory and mitigatory action. However, the future scope of research along these lines included proposing an alternative index for political instability. An ideal index should reflect level of state ownership and its correlation with corruption corresponding to years of greater unrest, level of minority representation at different levels of government and most importantly, the inevitable conflict against terror.

\subsection{The need for a functional Conflict-Growth Model}

The current global economic landscape constitutes economies such as the BRICS and the N-11, which are mostly emerging economies or rising powers. With economics - trade and economic strength - becoming the dominant determinant of foreign policy and diplomatic conduct, these countries are challenging the existing power configuration. However, these emerging market economies grapple with deep rooted developmental problems of their own. A shared trait between these countries is development or growth in the face of persistent conflict. With further globalization and increase in trade relations, the stake in international trade and investments in these economies is increasing, leading to growth. Due to a multitude of factors, several of which are listed in this paper and some not identified specifically, the development regime of emerging market 
economies is extremely volatile due to the influence exerted by the variety of factors, many of which are beyond state control and/or are intentionally state designed depending on the political system in place.

With the advent of the second decade of the millennium, the world saw a spate of conflict zones arising across the globe. Geopolitically, the modern Pivot or the Heartland shifted to the Middle East which witnessed conflict after conflict beginning with the Arab Spring to the Syrian crisis and the ISIS led activities currently in motion. Similarly, Africa and many parts of Asia are no stranger to conflicts regarding refugee issues, piracy, and conflicts along ethnic and cultural fault lines. The biggest victim of this uncertainty about the economic system and political situation is the general population, whose activities of livelihood are disrupted apart from loss of life. Economically, lack of preparedness leads to further economic frailty and violent fluctuations in the business cycle. As consumption levels suffer, these emerging market economies suffer supply shocks, shrinking of demand, massive disinvestment, which in turn affects the state's welfare motive. Research in the field of international political economy is now dealing with monitoring such areas for indicators that may prove as warning systems to prepare for - and if possible, avert - periods of great turmoil. While this paper does not comment on the mechanics or dynamics of the conflict itself, we would like to advocate strongly the need for a simple functional model which regresses political instability and economic so growth with relevant parameters such that simultaneous determination may yield a coefficient that indicates the level of impendence of conflict. We have further illustrated many of this paper's qualitative conclusions in favour of building a quantitative framework through a case study of Nigeria and Turkey - both emerging market economies which have been the most rapidly growing countries in their respective continents in the face of persistent and varied conflict.

\subsection{Illustrative Country Cases - Turkey \& Nigeria}

Turkey's birth as a republic back in 1923 under Kemal Ataturk has seen a whole spectrum of conflicts since. The nature of conflicts have ranged from border skirmishes due to its neighbouring countries of Syria, Iran and Iraq being home to a populace of ethnically diverse Kurds to internal uprisings in an effort to overthrow the government. Though a sizable minority in Turkey they have always been vocal about their sense of insecurity about the Turkish government trying to destroy their identity. But what is interesting to note here is that Turkey has been involved in a considerable number of conflicts in the region as well as outside the continent owing to its strong presence in the intergovernmental military alliance NATO as the second largest contributor of military personal to the NATO forces after the United States.

Some of the most widespread conflicts in Turkey were witnessed in the years 1991, 1994, 1995, 1997, 1999 and 2001 with respect to the area of conflict covered in square kilometres. Despite conflicts that covered areas as large as the size of Ireland within the country, it has managed to sustain an annual average growth rate of $4 \%$ over the last 2 and half decades which is rather promising considering the volatility of the region. Turkey's GDP growth rate exhibits a sharp decline for the years 1994, 1999 and 2001 when the area under conflicts was significantly large. Some years have even seen conflicts within as well as across the border in the region thus contributing to the decline in growth rates. The decline in growth rate in 1994 was in part due to a ratings downgrade and bleak outlook as a result of difference in opinion between the Turkish political leadership and the country's banking chiefs. But one cannot turn a blind eye to the war that was ensuing between Turkish forces and the PKK in large swathes of the country with the govt. forces trying to push back the PKK into the mountainous terrain and sanitizing cities and villages. Though the prolonged conflict $(1993-2001)$ with the PKK weighed heavy losses on the Turkish forces, they were able to flush out the PKK from major villages and cities. Even with high degree of human rights violations, data from the Prio Conflict Site dataset shows a recognizable pattern of decreasing area of conflict from 2001 onwards. Consequently, the GDP growth rate for Turkey somewhat stabilized averaging around 5.5\%, from 2002 through 2008. Its sharp decline around 2008-09 is rather intelligible with a globally integrated $\$ 600$ billion economy (2009 approx.) with a largely diversified service sector and major western economies as its export partners. Graphical representation of conflict area (sqr. kms.) and GDP growth rate datasets show a peculiar yet not entirely cryptic, positive correlation between them for the years 1995 and 1997 in particular. This leads us to the proposition that certain conflicts have either shown a marked increase in productivity of both labour and capital or were insignificant in terms of intensity notwithstanding the area covered by them to affect the growth trajectory markedly. It is commonly accepted that the conflicts play a role in daily devaluation of the Turkish lira against the US dollar. 
Centred on the tenet of free enterprise, Turkey had managed to capitalize on the strength of its exports while simultaneously cashing in on its geographical disposition as a tourism hotspot. Additionally, the separation of its cultural and political capitals between Istanbul and Ankara has been catalytic in spurring growth distancing trade, commerce and tourism of the Mediterranean from the more delicate political environment east of the region.

Turkey has managed to find its sweet spot between The Netherlands and Switzerland ahead of all other countries in the Middle East and North Africa region when raked up by GDP. This, despite no oil export industry, frequent in-land and regional turmoil and massive dependence on fossil fuel imports (97\%) is what makes Turkey an unparalleled growth story of our turbulent times.

According to the ACLED, Nigeria is a very active country given that the mandate of its datasets covers civil wars, non---government violence and violence against civilians. A large part of the data comes from information on political militias or the various actors that attack the military and civilians. With a total of 3379 events of political violence and an average count/year of 211 between 1997 and 2012, conflicts between armed groups account for roughly $32 \%$ of all events. Political militias dominate the main group of agents that are continuously contributing to Nigeria's staggering growth and unstable political climate. Violent conflicts have been increasing growing at approximately 9.8\% year on year since 1997 calculated from the ACLED dataset independently, more so since 2010. Nigeria's conflicts have temporal and spatial patterns as illustrated by the datasets. Battles, riots and violence against civilians paint the spatial spread while the temporal spread is discernible from the timeline of data.

The Boko Haram remains the largest and most high profile militant group trying to cement their presence through intricately organized insurgency structures with relatively nascent groups like the Ansaru building base. The Plateau region has the highest rates of fatalities per event of any Nigerian state, at 6.8 reported fatalities per conflict event. This is almost double the national average of 3.7. Studies have clearly shown that the trickling down of benefits to the population from the country's largest export commodity which is crude petroleum has been almost undersized due to the high degree of corruption within the Nigeria National Petroleum Corporation (NNPC). This has further impeded development in the country although it has trumped South Africa as the fastest growing economy in Africa.

Though the incidence of violence against civilians has risen sharply since President Goodluck Jonathan took office, the state has shown remarkable resilience against a background of Nigeria's changing strategic importance in the world. As more energy resources in the sub-Saharan region become lucrative, Nigeria's preponderance in the region is likely to wane as investors diversify their energy portfolio to minimise market risk from political instability subsumed by the common denominator of Islamist Extremism.

\section{Conclusion}

This paper has, after critically analyzing existing studies and models based on the conflict-growth relationship, attempted to identify the deficiencies in design and in terms of key parameters that have been overlooked and must be added in keeping up with the evolution of the current reality. It asks the important question whether conflict can be desirable for growth, as it also seeks to understand how different varieties and intensities of conflict have varied impacts on economic performance. It seeks to highlight certain anomalous trends for emerging market economies, wherein larger conflict areas sometimes coincides with an augmented macroeconomic performance. Furthermore, the paper grapples with the classic growth vs. development question within the larger framework of conflict duality. Importantly, the paper seeks to set the foundation stone on the need for a more functional model representing the said duality. An important starting point for such a model could be utilizing the Political Instability Index as a measure of conflict or political unrest, since it factors in economic, political as well as institutional variables that affect the interplay of parameters defining the conflictgrowth relationship. Lastly, but not the least, the paper calls for a model that is of utmost necessity to organizations monitoring conflict area indicators to prepare for and try to avert severe distress. Such models could be of great use to agencies and organizations that are affiliated to organizations such as the UN and other aid agencies that work in conflict areas in remediation efforts, rebuilding effort and for governments trying to rebuild a stable political and economic climate. It could also be of enormous help to scholars conducting research in peace studies, IPE etc. Finally, through the country cases of two emerging market economies Turkey and Nigeria - this paper attempts to illustrate the peculiarities in the development spectrum for such states. While Nigeria is severely affected in terms of inequality due to an extremely poor and corrupt 
institutional framework, Turkey is affected by conflict across its border, sub-conventional warfare, and conflicts due to ethnic and cultural fragmentation. This paper, therefore, reiterates the need for further study in the field along the lines laid out above.

\section{References}

[1] Raleigh, Clionadh \& Håvard Hegre, "Introducing ACLED: An Armed Conflict Location and Event Dataset," presented at the conference on 'Disaggregating the Study of Civil War and Transnational Violence', University of California Institute of Global Conflict and Cooperation, San Diego, CA, March 7-8, 2005.

[2] Hegre, Håvard \& Clionadh Raleigh, “'Population, Size, and Civil War. A Geographically Disaggregated Analysis," presented at annual meeting of the International Studies Association, San Diego, CA, March 22-25, 2006

[3] Country Report: Nigeria, Armed Conflict Location and Event Database, April 2013

[4] Dittrich Hallberg, Johan. (2012). 1989-2008: A Geo-Referenced Dataset on Armed Conflict. Conflict Management and Peace Science 29 219-232. Available: http://cmp.sagepub.com/cgi/content/abstract/29/2/219

[5] US Dept. of State (March -1996). Turkey Human Rights Practices, 1995. 6. Hellenic Resources Network. Available: http://www.hri.org/docs/USSD-Rights/95/Turkey95.html

[6] Kadri Gursel. (Sep -2005). 6 reasons why Turkey's war against the PKK won't last. Turkey Pulse - Al Monitor. Available: http://www.al-monitor.com/pulse/originals/2015/09/turkey-kurds-pkk-daglica-war-be-sustained-bloodyday.html\#

[7] Polachek S.W., Sevastianova D., "Does Conflict Disrupt Growth? Evidence of the Relationship between Political Instability and National Economic Performance," IZA DPS, vol. 4762, February 2010.

[8] Alesina A., Roubini N., Ozler S. and Swagel P. (September 1992). Political Instability and Economic Growth. Journal of Economic Growth 1(2): 189-211. Available: Harvard DASH Repository http://dx.doi.org/10.1007/BF00138862

[9] Barro R. (1991) "Human Capital and economic growth: Cross-country evidence from low, middle, and high income countries," Cambridge University Press, ISBN: 0-262-02421-7

[10] Easterly W., Rebelo S. (September 1993). Fiscal policy and economic growth: An empirical investigation Journal of Monetary Economics 32(1993) pp. 417-458

http://dx.doi.org/10.1016/0304-3932(93)90025-B

[11] Sreedharan S. and Shyamsunder S, "The Dynamics of International Political Economy: A Realist Perspective ISSN 2307-7549," presented at the $9^{\text {th }}$ International Conference on Economics and Social Sciences, Istanbul, USA, October $17-18,2015$

\section{Appendix 1}

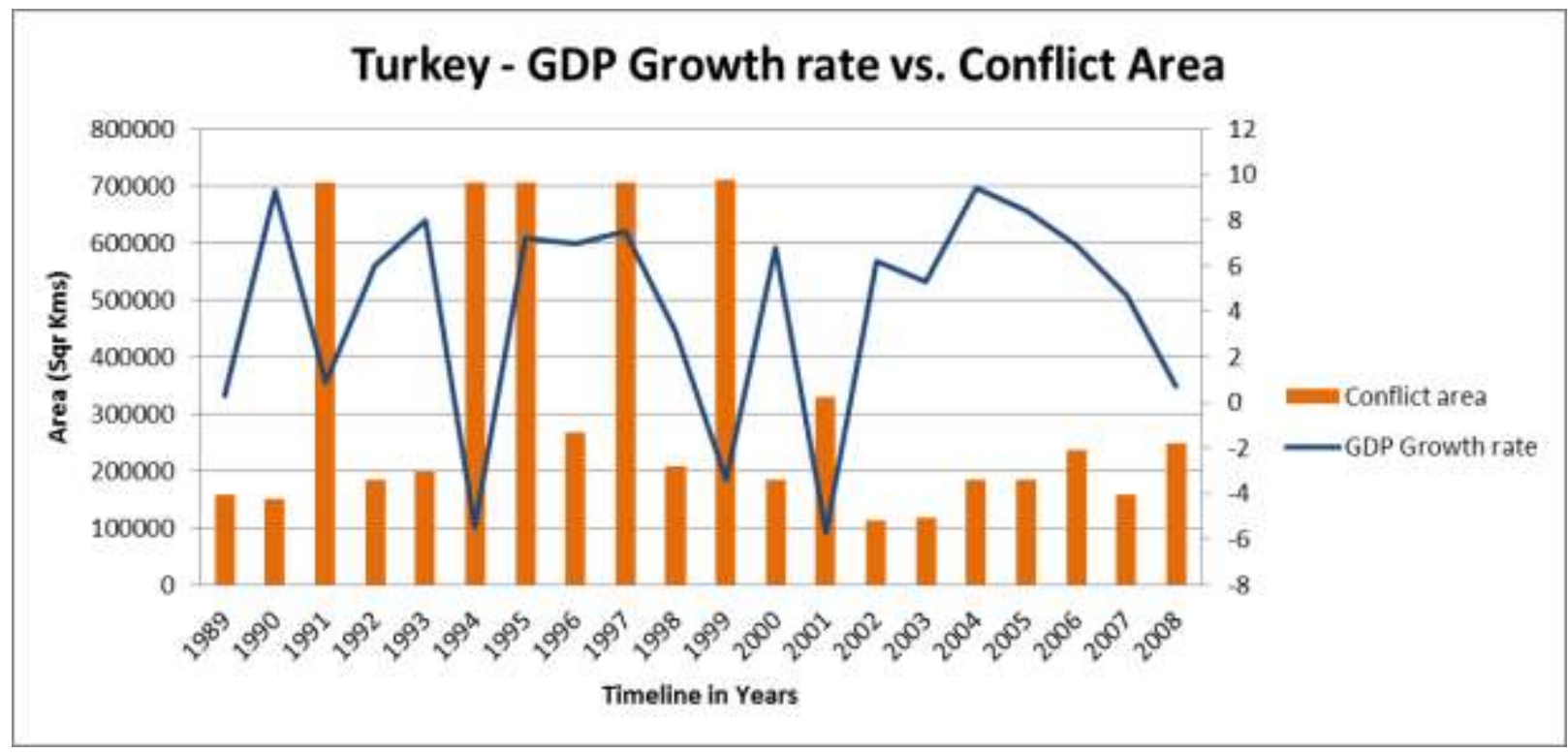

